\title{
Individuo, trabajo y neoliberalismo
}

David Esteban Rico Palacio

Universidad Eafit, Colombia 


\title{
Individuo, trabajo y neoliberalismo*
}

Resumen: en la sociedad neoliberal, que ha moldeado la figura de una subjetividad que asume riesgos y actúa por sus propios medios y por iniciativa privada, los procesos económicos se explican a partir de las conductas de individuos libres y racionales que acuden al mercado para insertarse en su dinámica de competencia. Con esto, las condiciones específicas y objetivas que definen la estructura social, la cual establece el marco de acción posible en la que los sujetos se comprenden y realizan sus fines, quedan relegadas a un segundo plano. Sin embargo, la sociedad no es solo el resultado de la acción espontánea de los individuos que la componen. Así, a partir de elementos aportados por la concepción marxiana de la sociedad capitalista, el presente artículo pone de relieve la necesidad de establecer la prioridad de la estructura social en tanto esta define el campo de acción de los individuos y condiciona sus resultados.

Palabras clave: neoliberalismo, individuo, sociedad, trabajo, libertad, Marx.

\section{Individual, work and neoliberalism}

\begin{abstract}
In the neoliberal society, which has molded the figure of a subjectivity that assumes risks and acts by their own means and by private initiative, economic processes are explained by the behavior of free and rational individuals who come to the market to insert themselves in its dynamics of competence. With this, the specific and objective conditions that define the social structure are lost sight of, which establishes the framework of possible action that covers individuals, in which they realize their ends. However, society is not only the result of the spontaneous action of the individuals that compose it. Thus, from some elements provided by the marxian conception of capitalist society, this article aims to highlight the need to establish the priority of the social structure, as it defines the field of action for individuals and conditions their results.
\end{abstract}

Keywords: neoliberalism, individual, society, work, freedom, Marx.

Fecha de recepción: 27 de julio de 2018

Fecha de aceptación: 30 de noviembre de 2018

Forma de citar (APA): Rico-Palacio, D. (2019). Individuo, trabajo y neoliberalismo. Revista Filosofía UIS, 18(1), doi: http://dx.doi.org/10.18273/revfil.v18n1-2019007

Forma de citar (Harvard): Rico-Palacio, D. (2019). Individuo, trabajo y neoliberalismo. Revista Filosofía UIS, 18(1), 151-170.

David Esteban Rico Palacio: colombiano. Magíster en Ética y Filosofía Política. Profesor Universidad Eafit, Colombia.

Correo electrónico: david.rico@udea.edu.co

ORCID: http://orcid.org/0000-0003-0440-665X

* Artículo de reflexión derivado de investigación. 


\section{Individuo, trabajo y neoliberalismo}

\section{Introducción}

En este texto se hará una aproximación crítica a la nueva imagen del trabajador independiente que surge en el contexto de la sociedad contemporánea. Esta nueva figura económica de la sociedad actual, que brota del seno de la economía neoliberal, es el eje central del análisis económico de esta época, el cual fija su estudio en la conducta y los comportamientos de los individuos que, a través de un cálculo racional, evalúan las posibilidades de acción tomando en cuenta sus pretensiones y proyecciones de utilidad y beneficio. Para ello se valoran los actos estratégicos de los individuos orientados a la identificación de espacios de inversión, previsión de riesgos, evaluación de posibilidades en el mercado, especulación, etc. El conocimiento de todo esto constituye el conjunto de principios, normas y premisas que debe regular la acción racional de los individuos, al tiempo que configura y comprende lo que se debe saber si se quiere ser partícipe de la nueva economía que configura la organización social del presente.

El estudio de los fenómenos sociales y políticos, basado en el análisis de las motivaciones de los individuos, prevaleció en la modernidad principalmente entre los autores contractualistas cuyo iniciador fue Thomas Hobbes. Estos autores legitimaron y explicaron la necesidad y la naturaleza de la sociedad civil partiendo de una reflexión del individuo y sus atributos inherentes, tales como derechos naturales, pasiones, afectos, razón, etc. Hegel, por su parte, diferenció sociedad civil de Estado, pues consideró que el fin de aquella, como momento de la totalidad ética, es la seguridad de la vida, la protección de la propiedad y la libertad individual; mientras el Estado, como realidad sustancial y universal, es el fundamento de la familia y la sociedad civil, y no puede justificarse su existencia en una mera relación contractual. El contrato, por fundarse en el arbitrio particular de la persona, presupone la contingencia y la casualidad. De ahí que con este sólo se haga referencia a los intereses específicos de los propietarios singulares y no pueda trascender por ello la esfera del derecho privado. Así pues, los contratos y las obligaciones que se derivan de él se dan sólo en el ámbito de la sociedad civil, que es el plano de las relaciones sociales y económicas privadas. 
Karl Marx, partiendo del análisis de la sociedad civil, consideró esencial tomar las relaciones sociales como principio fundamental para la comprensión de la estructura que define el conjunto de la organización social, y a los individuos los concibió como parte inseparable de las condiciones materiales de existencia en las que ellos se inscriben. En los Manuscritos económicos-filosóficos de 1844 había afirmado la necesidad de "evitar ante todo el hacer de nuevo de la "sociedad" una abstracción frente al individuo" (Marx, 1970, p. 146). Esta idea, que luego desarrollará de un modo más definido, es de la que parte Marx para realizar las investigaciones económicas que le permitirán ahondar en la naturaleza social específica del trabajo y sus productos, en la relación concreta entre capitalista y trabajador, y en la interacción del resto de determinaciones económicas con el fin de comprender sus conexiones esenciales (den wesentlichen Zusammenhang), o lo que es lo mismo, el modo necesario en que se establece la relación entre capital y trabajo.

\section{Individuo y sociedad}

Pensadores como Hobbes, Spinoza, Locke, Rousseau y Kant consideraron conveniente partir del estudio del hombre para conocer los fundamentos de la sociedad y el Estado. Comenzando por el análisis de la naturaleza humana y el movimiento de las pasiones, Hobbes dedujo de manera lógica la necesidad de una máquina artificial que él llamó Leviatán, creada por la voluntad de los hombres que, movidos por el miedo, se ven impulsados a crear un poder común lo suficientemente fuerte para evitar la posibilidad real de muerte violenta que surge en un hipotético estado de naturaleza. Esta operación lógico-deductiva no tomó como punto de partida de su investigación la consideración de las condiciones históricas específicas que pueden producir la guerra y posibilitar su superación, sino que, antes bien, partió del análisis moral del hombre (ethos) para conocer el mecanismo de funcionamiento que hace posible la creación del Estado para conseguir la paz. Esta es una práctica teórica común entre clásicos y neoclásicos, que toman al individuo y sus modos de actuación, supuestamente universales, como punto de partida para el análisis de formas sociales y económicas determinadas. Como consecuencia de este proceder metodológico, se tiende a "proyectar en los individuos una buena parte de la estructura social que pretenden explicar" (Heinrich, 2018, p. 79).

El materialismo mecanicista de Hobbes tomó la existencia física de los cuerpos como principio explicativo de la realidad y el pensamiento, pero nunca se le ocurrió tomar la realidad social concreta como punto de partida para el análisis de los individuos, para entender bajo qué condiciones los hombres realizaban sus actos y llevaban a cabo su existencia. Tuvieron que pasar dos siglos más para 
que Marx fundara lo que en su Tesis décima sobre Feuerbach llamó "materialismo nuevo" (neuen Materialismus), que parte de la "actividad sensible" de las personas como sujetos socialmente activos, lo cual pone en estrecha relación la historia y la praxis social como principio constitutivo de la realidad humana.

La perspectiva marxiana adoptó el punto de vista según el cual las prácticas sociales están condicionadas por el grado de evolución y desarrollo que ha alcanzado la organización de la sociedad en cada época. En los Grundrisse afirmó Marx (2007) que "la sociedad no consiste en individuos, sino que expresa la suma de las relaciones y condiciones en las que esos individuos se encuentran recíprocamente situados" (p. 204). La sociedad, entonces, es anterior a cualquier decisión racional individual, pues en realidad ella establece los parámetros que definen la racionalidad dentro de esas relaciones, ya que la totalidad de la estructura social está definida antes de que los hombres se encuentren con ella. De ahí que refiriéndose a la sociedad burguesa afirme que es "necesario el capital, pero en absoluto los capitalistas" (Marx, 2000, p. 30). Por esto es necesario conocer la relación principal entre capital y trabajo, y reconocer el carácter secundario que tienen las relaciones personales entre capitalista y obrero como agentes que expresan en sus relaciones una determinada estructura económica. A la moderna sociedad burguesa le es indiferente que el capital esté en tales o cuales manos, pues todo capital ahora existente "existe independientemente de, y de ningún modo se identifica con, un individuo particular o una clase particular [...] Es el capital, y no el capitalista, lo esencial para las operaciones del productor" (Marx, 2000, p. 31).

No son las personas las que determinan al capital, por el contrario, es el capital el que condiciona la acción y se sirve de los hombres para realizar a través de ellos su propio fin. De ahí que en El capital Marx denuncie el hecho de que la economía clásica no vea en el capitalista más que "una máquina para convertir la plusvalía en pluscapital" (Marx, 2014a, p. 531) ${ }^{1}$. En este sentido se expresa Alfred Schmidt (2011) cuando afirma que "Marx entiende los modos de conducta de los individuos como funciones del proceso objetivo. En la historia transcurrida hasta hoy los individuos se han presentado menos como sujetos libres que como 'personificación de categorías económicas'" (Schmidt, 2011, p. 40). Esta idea es también recogida por Karel Kosik (1979), quien en su obra Dialéctica de lo concreto escribe:

\footnotetext{
' Esta idea se amplía en el llamado Capítulo VI (Inédito), donde escribe Marx (2000): "Las funciones que ejerce el capitalista no son otra cosa que las funciones del capital mismo — del valor que se valoriza succionando trabajo vivo- ejercidas con conciencia y voluntad. El capitalista solo funciona en cuanto capital personificado, es el capital en cuanto persona; del mismo modo que el obrero funciona únicamente como trabajo personificado, que a él le pertenece como suplicio, como esfuerzo, pero que pertenece al capitalista como sustancia creadora y acrecedora de riqueza" (Marx, 2000, p. 19). Véase también en la misma obra pp. 49-55.
} 
Los hombres se convierten en portadores o ejecutores del movimiento de las cosas. La voluntad y la conciencia de los hombres se hallan determinadas por el movimiento objetivo de las cosas: el movimiento de las cosas se realiza a través de la voluntad y la conciencia de los hombres (Kosik, 1979, p. 210).

Así pues, si se quiere conocer el funcionamiento de la sociedad, no es suficiente tomar como objeto inicial de estudio la conducta de los individuos, pues aun cuando sus comportamientos sean conscientes y voluntarios no podrían fácilmente sustraerse del conjunto de relaciones que los disponen a actuar; no estaría en sus manos representar de una manera diferente el papel que prescribe una determinada configuración social, a través de la cual los individuos ponen en movimiento estructuras económicas que encarnan y personifican, esto es, estructuras reales que los condicionan a actuar y a ocupar un lugar específico en la producción social global; por lo cual, estos se comportan como representantes de relaciones sociales en las que se mueven y llevan a cabo sus acciones. Esto se reafirma con más fuerza en la formación económica específicamente capitalista, donde el trabajo ocupa un lugar primordial en su forma abstracta como productor de valores de cambio, y se convierte en principio constitutivo de relaciones sociales que articulan un nexo social humano a través de mercancías en tanto formas objetivadas de la mediación social que terminan condicionando todos los ámbitos de la vida humana ${ }^{2}$. En el análisis de Marx, la determinación específica del trabajo que produce mercancías para el intercambio constituye el medio por el cual se adquieren los bienes de otros productores con los que hay que entrar en contacto a través del mercado. En los Grundrisse se lee:

En la producción basada en el capital, empero, en todos los puntos el consumo está mediado por el intercambio y para el trabajador el trabajo nunca tiene valor de uso directo. La base entera de aquella es el trabajo como valor de cambio y como creador de valores de cambio (Marx, 2007, pp. 372-373).

Cada productor se sirve, pues, de su propio trabajo como un medio para acceder a los productos de los demás. Lo que se ofrece es una mercancía o un servicio que sirve de objeto útil para el consumidor, pero que esencialmente sirve de medio de intercambio para quien lo vende. Que el producto del trabajo sea un objeto útil es una condición social general de todo trabajo, pero que sea un objeto

\footnotetext{
2 Para un análisis más amplio y detenido de estas ideas, véase la obra Tiempo, trabajo y dominación social (2006) de Postone, quien basa su lectura de Marx en un famoso pasaje de los Grundrisse, para retomar la crítica marxiana del capitalismo, no a partir de la categoría de propiedad privada o mercado, sino a partir de algo más esencial: la categoría de valor. Según el autor, el valor expresa no solamente una forma histórica de la riqueza, sino que también da existencia a una determinada estructura de las relaciones sociales a partir del trabajo que lo produce. Este sería pues el punto de partida de la crítica a este régimen de producción. De ahí que afirme que "el análisis adecuado del capitalismo solo es posible si se parte de un análisis del carácter histórico específico del trabajo en el capitalismo" (Postone, 2006, p. 66).
} 
útil para otros y nunca para quien lo produce es la determinación económica históricamente específica de la sociedad capitalista. Que el producto nunca sea valor de uso inmediato para su dueño es una condición que la mercancía impone en tanto valor. La doble determinación de la mercancía como valor de uso y valor de cambio expresa, respectivamente, el doble carácter del trabajo como trabajo concreto y trabajo abstracto. En una sociedad de propietarios privados que producen independientemente unos de otros el trabajo sirve de mediador social dado que crea una configuración objetiva que obliga al intercambio de productos. Las relaciones sociales entre las personas dejan de ser relaciones abiertas y directas, justamente porque el trabajo se convierte en mediador social por el que las personas entran en contacto para adquirir los productos de los otros. No son los individuos los que directamente participan de la mediación social, sino que se trata más bien de una mediación social objetiva independiente de la voluntad de quienes intercambian, los cuales han entrado ya en una interdependencia general constituida por un tipo de trabajo que reemplaza las relaciones abiertas entre las personas.

En el amplio escenario de socialización que ofrece un mercado libre, abierto y "democrático" (al menos para aquellos que cumplan las condiciones de consumidor-productor), la cotidianidad permite que cualquier oportunidad, proceso o relación pueda convertirse en mercancía. El campo de oportunidades que el mercado brinda propicia la ocasión para que el sujeto gestor establezca "contactos" y conexiones estratégicas, recolecte información, desarrolle habilidades para competir e intercambie experiencias de mercado ${ }^{3}$, etc. Los valores que el mercado considera importantes no son los cívicos o los morales, sino solamente los de cambio. En el mundo de la libre competencia la sociedad queda reducida a un organismo compuesto por individuos que han roto los vínculos sociales y comunitarios; no son individuos solidarios ni socializados, sino átomos dispersos y aislados cuyo contacto social se produce gracias al mercado. No se relacionan como personas ni como ciudadanos, sino como comerciantes y hombres de negocios. A causa de los mecanismos de estandarización y mercantilización, de la sexualidad y la comunicación, por ejemplo, "la calidad de la existencia se ha deteriorado desde el punto de vista afectivo y psíquico como resultado del deterioro de los vínculos comunitarios" (Berardi, 2003, p. 65).

Ahora bien, en el capitalismo del siglo XIX que Marx estudió, con el producto del trabajo como mercancía, esto es, como materialización de trabajo abstracto

\footnotetext{
En su libro Alienación y aceleración social (2016), Harmut Rosa ha acuñado la expresión "promesa de eternidad" para explicar la aceleración continua del ritmo de vida (realización de más actividades en menos tiempo) y su relación con la experiencia en el mundo contemporáneo. Contra la finitud y la muerte se ha propuesto un sentido de plenitud y placer de la vida condicionados por el rendimiento, el goce ilimitado y la cantidad de experiencias consumidas y acumuladas. La tasa de crecimiento de las actividades (ritmo de vida, escasez de tiempo) ha concebido la idea de vida buena como vida colmada de sensaciones. Por lo general, una vida intensa, llena de emociones administradas y experiencias organizadas por atractivos paquetes comerciales (pp. 21-39).
} 
medido por el tiempo social medio necesario, se realiza la objetivación que da vida a una determinada estructura socialmente mediadora. En una palabra, el trabajo productor de mercancías constituye una estructura que da forma a un determinado sistema de relaciones sociales a través de las cosas, a esto es lo que Marx llama fetichismo. De esta manera, no solo el trabajo, sino también su producto y las relaciones sociales que aquel configura adquieren un carácter objetivo que impone la necesidad del intercambio, por lo que cada cual se ve obligado a empezar siempre el mismo proceso a través del intercambio continuo de productos. En el mundo contemporáneo se ha reducido, o incluso aniquilado, la posibilidad del vínculo social; este se ha hecho fugaz o imperceptible en la medida en que las nuevas tecnologías reducen el tiempo mediante un rapidísimo acceso a los clientes a través de enormes bases de datos, y establece formas de pago virtuales como formas de mediación absolutamente impersonales.

Volviendo al análisis de Marx de la sociabilidad mediada por mercancías, es preciso reiterar el carácter particular del producto del trabajo en tanto valor de uso con una existencia específica, y su atributo social general, ya que este es un valor de cambio que sirve de medio para la adquisición de los bienes de otros, sean cuales sean sus atributos físicos. Esta naturaleza social-general de la mercancía dada por el valor, que permite hacer abstracción de las cualidades físicas como condición para el intercambio es el elemento primordial de la producción capitalista con la cual se origina la mediación social.

\begin{abstract}
Las relaciones sociales que definen básicamente el capitalismo tienen carácter "objetivo" e integran un "sistema" debido a que están constituidas por el trabajo como actividad de mediación social históricamente específica [...] La acción social se encuentra condicionada, a su vez, por los modos de aparición de esas estructuras fundamentales" (Postone, 2006, pp. 175-176. Cursiva propia).
\end{abstract}

De esta manera, los individuos "libres" se encuentran con una serie de estructuras sociales de naturaleza impersonal, pero objetivas que ejercen sobre ellos una dominación social que moldea y produce un ámbito de acción que parece incondicionado y natural. En este sentido se afirma en los Grundrisse que "los individuos parecen independientes [...], parecen libres de enfrentarse unos a otros e intercambiar en esa libertad. Pero pueden parecer como tales solo ante quien se abstrae de las condiciones de existencia bajo las cuales estos individuos entran en contacto" (Marx, 2007, p. 91).

\title{
3. Trabajo y sociedad neoliberal
}

Después de exponer la naturaleza de los productos del trabajo como mercancías y las condiciones que hacen posible las operaciones de intercambio entre ellas, Marx procede en El capital a introducir a los poseedores de mercancías 
y los actos de intercambio que se realizan entre ellos. De esta manera, una vez expuesto el marco establecido por la producción de mercancías, Marx analiza el ámbito de la circulación y las actividades mercantiles de las personas bajo los parámetros que configuran sus relaciones mediadas por el intercambio. Toda esta estructura social es el supuesto de las acciones posibles de los que participan en ella como agentes en el marco establecido por la producción de mercancías (Heinrich, 2018, p. 116). Así mismo considera Maurice Godelier, quien en su libro Racionalidad e irracionalidad en economía (1975), afirma que "no se puede partir de los individuos y de la forma general de comportamiento orientado a un fin para analizar el contenido de la racionalidad de los sistemas y de los agentes económicos" (p. 26) $)^{4}$.

Sin embargo, en el contexto de la actual sociedad neoliberal el trabajo es concebido como una actividad libre que los sujetos despliegan en un ámbito abierto carente de restricciones y límites, llevada a cabo por individuos racionales que se proponen un objetivo: extraer la máxima ganancia mediante el menor gasto posible de recursos. Este marco de comprensión es defendido por la economía neoclásica la cual "parte de los individuos que maximizan su utilidad y fundamenta las relaciones de cambio en los cálculos de utilidad que realizan los individuos" (Heinrich, 2018, p. 79).

En el mundo neoliberal la economía no está muy interesada en estudiar las estructuras económicas, la posición social de las personas, ni los mecanismos de producción o de intercambio, ella prefiere concentrarse en el análisis del comportamiento humano a partir de la relación medios y fines. Para el neoliberalismo, escribe Foucault (2007) citando a Lionel Charles Robbins, "la economía es la ciencia del comportamiento humano" (p. 260). Con ello, la economía deja de ser el análisis de procesos y toma principalmente en cuenta la conducta, los fines y los cálculos racionales de quienes emprenden una acción estratégica dentro del mercado. El cálculo racional, el goce, el placer y las preferencias subjetivas son los elementos que se tienen en cuenta para considerar al individuo en la actividad que desempeña. El individuo despliega su acción como un resultado del cálculo que debe producir los mayores resultados, por lo que cada cual debe examinar los medios más efectivos para alcanzar metas más altas y rentables que lo conduzcan al éxito y al triunfo de su empresa.

Con frecuencia cada vez mayor, por tanto, el trabajador se considera su propio empresario y, en el plano jurídico, lo es. En el plano sustancial, la autonomía de este trabajador empresario es una pura ficción, pues no es él quien decide los planes a largo plazo, las modalidades de desarrollo de la actividad, etc. (Berardi, 2003, p. 73).

\footnotetext{
${ }^{4}$ Más adelante en la misma obra insiste en esta idea cuando escribe: "No es posible partir de los individuos para explicar el contenido y la jerarquía de sus necesidades, de su valor y de su objetivo" (Godelier, 1975, p. 44).
} 
Con la figura del empresario de sí mismo, analizada por Foucault y tan profusamente invocada en esta época, se alude a un tipo de individuo que se ve impelido a asumirse como una persona que gestiona los recursos de los que dispone para poder competir. Ser empresario de sí significa proyectarse, capitalizarse, invertir en sí mismo, modelar la conducta y generar una nueva subjetividad en consonancia con el mercado.

Para analizar al trabajador 'empresario de sí mismo', es necesario, pues, pasar al exterior del trabajo: abandonar el análisis de las estructuras del proceso económico, y centrarnos en el análisis del individuo, de su subjetividad y de las condiciones de producción de vida (Gómez, 2017, p. 74).

La libre concurrencia es presentada en el neoliberalismo como un espacio que brinda ilimitadas posibilidades para el éxito individual. Basta con que cada quien asuma retos y defina claramente sus propios fines y propósitos. El dinero, el prestigio, la reputación, la obtención de logros y la conquista de metas, en una palabra, el éxito social y económico parecieran estar disponibles para quien desea acudir a ellos. El esfuerzo y el compromiso individuales se vuelven virtudes que previenen contra el fracaso y la mediocridad. Cada quien es dueño de sí mismo y cada uno está a cargo de su propio yo. La derrota está proscrita y el fracaso está excluido como opción. Triunfar, tal es la meta con la que los hombres estereotipadamente felices y optimistas de nuestra época se levantan cada día y emprenden su tarea diaria: la de ser los dueños de sí mismos, administradores de su tiempo y jefes de su propia empresa.

Sin embargo, acceder al reino prometido de la realización individual no es tan fácil como arguyen los admiradores optimistas del modelo neoliberal. En la carrera frenética por alcanzar la meta muchos empresarios entusiastas se quedan a lo largo del camino. Las cifras en Colombia son reveladoras. Según el estudio de Confecámaras (2018) sobre el comportamiento empresarial en 2017, el $70 \%$ de las empresas que nacen en Colombia logran mantenerse durante el primer año, pero 6 de cada 10 empresas fracasan antes del quinto año de su fundación, y del total de empresas que se cancelan cada año cerca del 98\% son microempresas. Según Romo (2016), “aunque en el país se crean muchas empresas cada año, la tasa de supervivencia de los nuevos emprendimientos es baja, 29,7\%". En países de la OCDE como Reino Unido, Italia y Francia las empresas tienen una tasa de supervivencia mayor, cercana al 50\%. Entre las causas de los cierres se menciona la falta de planeación, errores de gestión, escasez de recursos financieros y desinformación del mercado que dificulta la toma de decisiones. El emprendedor tiene que enfrentarse a un sinnúmero de factores para entrar en un mercado invadido por grandes capitales que son los que en definitiva dominan el mercado. De hecho, el capital económico y las ganancias proporcionales condicionan en gran medida el mantenimiento a largo 
plazo de un proyecto empresarial. Según el estudio ya citado, "solo un pequeño número de empresas grandes concentran el 91\% de las exportaciones totales de Colombia, las pymes participan apenas con el $8 \%$ de las exportaciones y las microempresas aglutinan solo el 1\%" (Vega, 2016).

Las condiciones desiguales de oportunidad, fruto de la diversa posición social de los participantes que se aventuran a emprender, son poco relevantes para el neoliberalismo, dado que este "parte de que todos los individuos, aun los que se encuentran en las márgenes de la sociedad, tienen la capacidad de incrementar su 'capital humano' mediante la creación, la innovación y el emprendimiento" (Castro-Gómez, 2010 p. 51). No obstante, el modelo de sociedad neoliberal no puede hacer efectivas las aspiraciones de todos los que se arriesgan a conquistar sus jugosas promesas. En el sueño empresarial de emprendedores independientes, aunque de una forma no tan evidente, la posibilidad real de éxito es bastante incierta para la mayoría que cae seducida por el cebo astuto de vendedores de humo y sueños vaporosos. Bastaría con reconocer el carácter excluyente de esta sociedad para poner en entredicho la totalidad del funcionamiento de un sistema que está diseñado justamente de ese modo, que no puede funcionar de otra manera, y que está obligado a crear la apariencia de que sus compuertas están abiertas para quienes deseen entrar. Con su dogma de la libre competencia individual, la sociedad neoliberal adopta un aspecto libre y democrático que promete a sus contribuyentes, en un reino de igualdad, hacer parte del goce y la riqueza, y ser miembro activo de los mecanismos que permiten la realización individual de sus participantes. Frente a esta apariencia había escrito Marx (2007) en los Grundrisse que en las relaciones monetarias capitalistas, y "en el sistema de cambio desarrollado (y esta apariencia es seductora para los demócratas) los vínculos de dependencia personal, las diferencias de sangre, de educación, etc., son de hecho destruidos, desagarrados [...], y los individuos parecen independientes" (p. 91).

La obligación de ascender y ser más excluye la posibilidad del fracaso y la derrota. Los discursos alentadores de la superación personal aconsejan la necesidad de crecer como una medida contra la resignación y el conformismo. Sin embargo, la autorrealización y los esfuerzos constantes de superación se dan en medio de un sentimiento incesante de insatisfacción y descontento. No se está conforme ni a gusto con lo que se es o lo que se tiene, y la sensación de que algo falta es cada vez mayor. En su análisis de los afectos, Spinoza identificó el deseo como la esencia misma del hombre. Pues bien, es justamente de eso de lo que se trata aquí: "Desear otra cosa; pero, sobre todo, es desear constantemente, desear más como manifestación de disconformidad fundamental consigo mismo" (Bedoya, 2018, p. 65). La actitud y la actividad deben orientarse a satisfacer y obtener lo que sirve de medio para acrecentar la personalidad del que desea. El cumplimiento continuo del deseo debe asegurar su movimiento constante $y$, al mismo tiempo, su acrecentamiento. 
Desde su concepción mecanicista, que concibe la vida como movimiento que no puede darse sin deseo, ya que "no tener deseos es estar muerto", Thomas Hobbes (1994) había anticipado la idea moderna de felicidad cuando la definió como "un continuo progreso de los deseos de un objeto a otro" (p. 79), o como "el éxito continuo en la obtención de aquellas cosas que el hombre desea de tiempo de tiempo" (p. 50). Esta definición propia del mundo burgués fue actualizada por el discurso neoliberal que tomó el deseo, el éxito y la felicidad para articularlos con el consumo y la competencia en el mercado. Con esto no solo se promueve el deseo, sino que se vuelve un medio para estimular a las personas para que sean más, para que sean mejores. Desear y gastar aparecen como una inversión: son medios productivos para la capitalización de sí mismo. Por eso el deseo y el consumo constituyen un proceso de producción cuyo resultado es la continua formación y restructuración de las personas, su autorrealización. De este modo, la monotonía circular de la reproducción de la apetencia queda superada ante la línea ascendente que describe la trayectoria del deseo y el consumo, los cuales se ponen al servicio del mejoramiento y la superación. Ya no se trata solo de un deseo cuyo cumplimiento salta de nuevo hacia otro objeto cualquiera, indiferente. No, ahora el deseo aparece revestido de un sentido y una finalidad, pues se pone en función de la inversión y el progreso. Es en este sentido que la acumulación de experiencias y apetitos cumplidos se convierte en un proceso formativo de alta cualificación y despliegue de capacidades.

Desde la perspectiva de los individuos se produce una lucha competitiva constante en materia de grados académicos, puestos de jerarquía en el trabajo, ingresos, bienes de consumo ostentosos, éxito de los hijos, pero también en cuanto a ganar y conservar una esposa y un cierto número de amigos (Rosa, 2016, p. 44).

El individuo tiene libertad de sentir y desear lo que quiera, siempre y cuando eso que desea y siente sea mercadeable. Bedoya (2018) ha distinguido entre "liberalización de las emociones" y "libertad emocional". El mercado promueve aquella, pero inhibe esta. Al respecto afirma que "la racionalidad neoliberal permite la libre emocionalidad como forma de gobierno de las personas. Pero esta libre emocionalidad es capturada por la lógica del mercado" (p. 71). Se es libre, sí, pero solo para cumplir las expectativas del mercado.

La formación y constitución de un tipo de individuo a través de instituciones, prácticas sociales, concepciones morales, filosóficas y declaraciones discursivas encaminadas a organizar un determinado tipo de subjetividad, se lleva cabo en el ámbito de la estructura neoliberal con su "dispositivo" empresarial. El dispositivo es la red que se teje a través de la articulación sistemática de todos estos elementos heterogéneos (Martínez, 2013). Con esta red se captura a las personas, pero sobre todo ella sirve para producir y moldear su subjetividad. Esto significa que, más que una ideología o un sistema de creencias que pone a actuar a los convencidos, 
el neoliberalismo es en realidad una especie de racionalidad con una estructura social concreta que cuenta con una serie de recursos, prácticas y estrategias dentro de las cuales se comprenden las personas. El neoliberalismo no depende de la conciencia que se tenga de él. Más bien esta depende de una estructura que posee mecanismos con los cuales produce una manera de actuar y creer, un modo de hacer y pensar que configura prácticas, aspiraciones, opiniones y elecciones de las personas. Sin embargo, hacer visible este dispositivo para mostrar la forma en que están siendo constituidos los individuos es el primer paso para denunciar este tipo de estructura y aspirar a su trrasnformación.

El individuo de hoy es una persona responsable de su actividad económica y del éxito social. Él se erige en juez implacable de los medios que emplea para su progreso y su realización. Si la esperanza de éxito no se hace efectiva, el fracaso deberá recaer en los hombros de quien lo padece, jamás en los defectos del sistema que lo produce. El conocimiento y la potencia de lo que cada uno es y podría llegar a ser, de la facultad o incapacidad para conseguirlo, se encuentran en él mismo en tanto juzga, examina y hace. Cada quien se asume en el papel que toma muy en serio la evaluación de sus habilidades para reconocer las posibilidades de evolución y ascenso en un marco de competitividad en el que el otro es un adversario o un medio para realizar los propios fines. En efecto, la de hoy es "una individualidad acostumbrada a concebir al otro según las reglas de la competencia, es decir, como un peligro, como un empobrecimiento, como un límite, más que como una experiencia, un placer, una forma de enriquecimiento" (Berardi, 2003, p. 65).

Con la figura del empresario de sí mismo la sociedad neoliberal ha podido forjar e interiorizar en las personas la imagen del sujeto de rendimiento altamente productivo y eficaz que hace uso disciplinado del tiempo y lo invierte, previo cálculo racional, en actividades económicas que lo benefician. Este trabajador autónomo que no tiene jefe, ni patrón, ni está obligado a cumplir horario en jornada fija laboral, deviene amo y señor de su tiempo para hacer empresa, pero dada la necesidad de aprovechar el tiempo, acelerar procesos y optimizar recursos para maximizar los beneficios, termina convirtiendo el tiempo libre que le queda en tiempo de trabajo. De modo que "cuanto más quieren ganar tanto más de su tiempo deben sacrificar, y enajenándose de toda libertad, han de realizar, en aras de la codicia, un trabajo de esclavos" (Marx, 1970, p. 54). El capitalismo estructuró la sociedad de tal modo que moldeó a su conveniencia todas las actividades, incluso las de ocio o tiempo libre; hizo de la sociedad una gran empresa, y convirtió el tiempo de la gente en tiempo de trabajo. Parafraseando a Byung-Chul Han, escribe el profesor Bedoya (2018): "El sujeto que se hace empresario de sí se convierte en un "esclavo absoluto", en la medida en que ya no está sometido privilegiadamente a la explotación ajena sino a la autoexplotación en su propia empresa" (p. 61). Este sujeto neoliberal, o "neosujeto" como lo llaman Laval y 
Dardot (2013), es un gestor de la empresa que asume como proyecto de vida. Él gestiona su salud, su educación, su renta, sus prestaciones y salario. Su vida es la constante búsqueda de una formación a cuyo servicio pone a disposición todo su capital humano: tiempo, saberes, energía, afecto, profesión, dinero, etc. En su afán de desproteger al ciudadano y promover al empresario, la sociedad neoliberal ha hallado formas efectivas para desmontar derechos y garantías que los trabajadores con sus luchas y demandas habían ido conquistando.

A diferencia del trabajador asalariado clásico, a quien el empresario debía garantizar una cobertura asistencial, una pensión y vacaciones pagadas, el trabajador autónomo debe hacerse cargo de tal protección, descargando así al capitalista de los costes indirectos del trabajo (Berardi, 2003, p. 74).

Ahora bien, con la invención del trabajador autónomo ella ha encontrado mecanismos con que interiorizar en cada uno la idea del mérito y la estimación como resultado de su propio trabajo y sacrificio. En la necesidad de probar su valor a través del trabajo reside el deber que cada uno tiene de cargar con los resultados, los cuales trascienden el ámbito de lo económico, pues compromete aspectos sociales y morales, incluso psicológicos. En la apuesta se pone en juego el amor propio y el sentimiento de sí mismo. El éxito potencia el ánimo para seguir triunfando, y promueve, se supone, la felicidad; el fracaso empobrece la existencia y crea seres tristes. En este sentido escribe Harmut Rosa (2016): "Todos sabemos que podemos perder nuestra ventaja competitiva en la lucha por las vinculaciones sociales: si no demostramos ser lo suficientemente agradables, interesantes, entretenidos y atractivos, nuestros amigos ya no nos llamarán" (p. 44).

La culpa se traslada a un ámbito privado de administración, y cada uno debe rendir cuentas a sí mismo ante el tribunal acusatorio de su razón instrumental. Ante el fracaso, la necesidad de levantarse y de "empezar otra vez" debe nacer precisamente de todo lo que debilita y hace sentir a cada uno el malestar de estar consigo mismo inconforme. Su condición (si no quiere decaer y perecer, si no quiere dejarse absorber por la pérdida de su estima y amor propio, por el sentimiento de insatisfacción que acusa su existencia) deberá servir de estímulo para superar las barreras que lo separan de sí mismo. Todo el ánimo transformador se dirigirá entonces hacia adentro en un trabajo introspectivo de autoayuda. De modo que la realidad externa no se pone en cuestión, pues lo que hay que modificar no es la estructura social sino los patrones de conducta. En vez de revolucionarios, se producen individuos deprimidos y seres aislados. Según Berardi (2003), “la depresión se presenta entonces como una enfermedad de la responsabilidad en la que domina el sentimiento de insuficiencia. El deprimido no está a la altura, está cansado de tener que ser él mismo" (p. 81). Cada quien deviene para sí su propio obstáculo y su propio salvador; el enemigo que debe ser vencido, el artífice de su victoria. De ahí la necesidad de franquear las barreras 
que limitan su acción y derribar en su propio interior las limitaciones que impiden su realización y la evolución de su personalidad.

Ante la amenaza constante de la incertidumbre, la inseguridad, la inestabilidad y el riesgo; ante el acoso de la soledad, la depresión, el estrés y la frustración, el mercado ofrece estimulantes, narcóticos y energizantes propulsores de la voluntad que prometen ayudar a superar el desaliento, el cansancio y el agotamiento de tal modo que se pueda potenciar el ánimo y resucitar el deseo, y acoger de nuevo cada día los principios que imponen por decreto el deber de ser felices. La vulnerabilidad y el riesgo que suponen la sociedad de mercado neoliberal demandan un espíritu dinámico y flexible, móvil y fácilmente adaptable, pero también una voluntad decidida, aventurera, osada, casi heroica. Como escribe Bedoya (2018): "Ser flexible y adaptado significa desarrollar la conciencia de que ningún obstáculo pone límite a las propias capacidades y a la generación de flujos de ingresos" (p. 64). Así pues, la contingencia de las circunstancias y el devenir accidentado e impredecible exige un individuo capaz de sortear la incertidumbre propia del mercado. Este individuo debe estar en capacidad de hacer gestión del riesgo, prevenir con pólizas y seguros que puedan reducir las consecuencias del peligro al que se encuentra sometido. Sin embargo, lo más importante es estar capacitado para reducir el azar y asegurar el éxito con los recursos subjetivos con los que cada uno cuenta, esto es, potenciar y hacer uso adecuado y eficaz de su capital humano. Si la persona misma es su capital puesto en acción, lo que importa entonces no es tanto producir, sino producirse, capitalizarse. Lo importante no es la productividad sino la competencia y el afán de desarrollar nuevas habilidades y nuevas cualidades que puedan responder a las exigencias de un mercado que devora mercancías, lugares y sujetos.

\section{Trabajo y capital}

En el análisis de la sociedad capitalista que hace Marx, en el contrato "libre" de la compra y venta de la fuerza de trabajo pactado entre las clases, "el poseedor de la capacidad laboral se enfrenta al capital o al capitalista como vendedor de aquella" (Marx, 2000, p. 79). En el contexto neoliberal, donde se pretende superar este enfrentamiento, esa oposición, como se verá más adelante, queda rota en apariencia. Por ahora el individuo se convierte en dueño absoluto de su capacidad laboral como capital humano, pero es también el que, bajo las nuevas condiciones, se enfrentará a sí mismo. Surge entonces una oposición interior que se vuelve un incentivo para querer ser siempre más, para superarse, para ir "más allá de sí" (Laval y Dardot, 2013, p. 361). De ahí que la superación personal se vuelva una obsesión y se convierta en el motor principal de toda actividad económica que emprenden los sujetos. Esta oposición consigo mismo para superar los propios límites no da mucha importancia a la estructura social y a las condiciones objetivas del trabajo (capital, objetos de trabajo y medios de producción) que antes se enfrentaban al 
obrero como propiedad ajena. Las limitaciones materiales de carácter económico y social se vuelven ahora restricciones psíquicas, taras mentales o impedimentos psicológicos, obstáculos propios de una voluntad flexible y pesimista que no ha puesto aún a prueba su fuerza interior, ni el poder de su convicción.

El sentimiento de sí, la fuerza que potencia o disminuye la capacidad de obrar, depende de las derrotas y conquistas que cada quien pueda alcanzar. Cada uno debe ser consciente de lo que quiere y de los medios a los que debe acudir para conseguirlo. Esto asegura el manejo de su voluntad de poder y permite el ejercicio de su autonomía. Ya Nietzsche (2002) había exclamado: "No apaciguamiento, sino más poder", por lo cual definió la felicidad como "el sentimiento de que el poder crece, de que una resistencia queda superada" (p. 32). Lo importante en el contexto neoliberal es que el individuo haga y sienta que con su actividad está creciendo; que se represente a sí mismo como un conquistador y un victorioso cuyos logros obedecen a sus méritos y no a la sociedad, a la que no le debe nada. Su realización continua es su felicidad. Lo paradójico de todo esto es que el individuo pretendidamente independiente y autónomo está atravesado por discursos, cánones y prácticas que le dictan cómo debe hacer la gestión de sí mismo. Se trata de una gestión inducida, o una "autogestión conducida" (Bedoya, 2018, p. 109) en la que interviene un ejército de expertos siempre listo para asesorar, entrenar, recomendar, formar, motivar, capacitar, aconsejar, etc. La contradicción no resuelta entre autogestión y guía termina por velar las relaciones de poder y dependencia en que están sumergidos los sujetos ${ }^{5}$.

Mientras tanto, el mundo social exterior, excluyente, inequitativo y desigual, estructurado por grupos económicos y clases dominantes (el mundo en el que la mitad de la riqueza mundial está en manos del $1 \%$ de la población; en el que el "82\% del dinero que se generó en 2017 fue al 1\% más rico de la población global" [Hope, 2018]), ya no se enfrentaría al trabajador, pues aquí el obrero ya no existe más, ha devenido empresario de sí mismo y dueño de las condiciones objetivas del trabajo, las cuales coinciden con las condiciones subjetivas de las que dispone cada uno en términos de habilidades y destrezas. Con el provecho que extrae de su "ventaja comparativa", el trabajador deja de ser concebido como un individuo que se pone a disposición de otros para que lo contraten; ya no será más el que ofrece su fuerza de trabajo para que sea empleada por un lapso determinado después de un acuerdo laboral. Más bien, la figura del nuevo trabajador autónomo ha devenido en persona activa y recursiva, competente y productiva, dueña de sí misma en tanto poseedora libre de la propia actividad que gestiona y organiza, pues su empresa la concibe como "invención y acción libre"

\footnotetext{
${ }^{5}$ La representación de que el trabajador por cuenta propia es un emprendedor ha ido velando la creciente falta de puestos de trabajo y la precarización producto de políticas de flexibilización laboral. Las plataformas digitales aparecen como una oportunidad para la independización laboral y la autonomía económica, pero en el fondo profundiza la precarización y genera prácticas de sobreexplotación a través de una "relación laboral disfrazada" (Coronel, 2018).
} 
(Berardi, 2003, p. 63). En suma, en la figura del empresario de sí mismo, con su capital humano, quedaría superada la premisa que Marx puso de relieve en su análisis de la relación entre capital y trabajo en la sociedad burguesa:

El fundamento real del que hubo que arrancar; el punto de partida del proceso de producción capitalista, fue el divorcio entre el producto del trabajo y el trabajo mismo, entre las condiciones objetivas del trabajo y la fuerza subjetiva del trabajo (Marx, 2014a, p. 508).

Sin embargo, con la figura del empresario de sí, del trabajador independiente que se erige en "capitalista de sí mismo", se consuma la supresión ilusoria de varias cosas: i) del carácter ajeno de la fuerza de trabajo y sus productos (pues la actividad del que hace la labor de empresario es tomada por este como propiedad exclusiva suya); ii) de las relaciones de explotación (pues el capital ya no sería más trabajo muerto objetivado que se le opone y se le enfrenta como cosa extraña y ajena, sino, por el contrario, trabajo vivo que se identifica con la persona de quien pone en movimiento su propio capital humano, es decir, los factores materiales, físicos y psíquicos que lo habilitan para producir ingresos) ${ }^{6}$; iii) de la condición de obrero o asalariado (pues él solo se concibe como trabajador independiente o individuo-empresario que ejerce una labor en donde actúa con ingenio y por iniciativa privada) ${ }^{7}$; iv) del carácter alienante o negador de la actividad productiva (pues el trabajo, sin importar cuán extenuante sea, aparecería como una actividad afirmativa y libre que produce goce, por lo que cada quien emprende la acción que más le satisface; y v) del carácter privado de la riqueza (pues todos tienen en su cuerpo la fuente futura de su renta y sus ingresos), lo cual implica una aparente socialización del capital económico, y la supuesta democratización de la riqueza. Además, la concepción del capital como "capital humano" es la garantía que protege contra el monopolio, que se torna imposible, pues cada quien participa en el mercado con su propio y exclusivo capital. Nadie puede apoderarse de él o arrebatárselo, ya que todos pueden libremente disponer de sus propias competencias y naturaleza individual en tanto medios que les permiten insertarse como empresarios listos para competir. Esta multiplicidad de capitales humanos hace que el juego económico se desarrolle en medio de una sociedad compuesta por "unidades empresas" (Foucault, 2007, p. 264).

Aptitud, actitud, idoneidad, capacidad para hacer: tales son las virtudes del trabajador que se inscribe en el contexto del neoliberalismo. Él es su propia

\footnotetext{
${ }^{6}$ Estos ingresos no tienen que dejar ganancias elevadas, incluso pueden representar solo lo suficiente para subsistir, pero eleva la satisfacción de hablar y actuar desde lo propio, pues el ingreso es el producto de la propia acción, se identifica con el propio cuerpo, con la propia vida. "El capital definido como lo que hace una renta futura - renta que es el salario- es un capital prácticamente indisoluble de su poseedor" (Foucault, 2007, p. 263).

"El trabajador independiente (selfemploying labourer), a modo de ejemplo, es su propio asalariado, sus propios medios de producción se le enfrentan en la imaginación como capital. En su condición de capitalista de sí mismo, se autoemplea como asalariado" (Marx, 2000, p. 82).
} 
inversión y patrimonio, el encargado de asegurarse estándares de cualificación que hagan de su "capital humano" un poder más seguro y efectivo. Cuida de sí mismo como de una gran riqueza que debe conservar y optimizar, mejorar y aumentar para entrar en el mercado, del que extraería la renta que debe acrecentar siempre. Este individuo que es una "unidad-empresa", este empresario de sí mismo, bien puede ser definido con las palabras que Marx empleaba cuando en 1844 describía al trabajador asalariado como una "mercancía con conciencia y actividad propias" (Marx, 1970, p. 125). En una palabra, el sujeto neoliberal independiente y "libre" que se concibe como capital humano, necesitado de un proceso continuo de formación, aprendizaje y capacitación, es la empresa personificada como "mercancía humana", con voluntad y consciencia.

\section{Conclusión}

En el contexto de la sociedad neoliberal contemporánea, el sujeto se ha erigido en una potencia autónoma cuya acción social y económica se explica a la luz de los cálculos racionales que buscan optimizar resultados a partir de la mayor economía posible de medios. El individuo es concebido como un agente libre que actúa, decide y emprende voluntariamente tareas que ponen a prueba su talento, su inventiva y su propia capacidad, asumiendo riesgos y responsabilidades que terminan por descargar sobre él el peso de estructuras sociales que han velado con astucia su carácter excluyente, privatizador, individualista y egoísta.

En el análisis de Marx, los individuos aparecen como personificaciones de categorías económicas, esto es, como agentes representantes de los factores que estructuran y definen las relaciones personales en el proceso global de la sociedad. Cada individuo encarna de hecho las contradicciones, oposiciones y dependencias sobre las cuales se alza el conjunto de la organización social. De ahí que ningún sujeto en particular pueda ser responsable de "la existencia de condiciones de las que él es socialmente producto" (Marx, 2014b, p. 10), pues por más que subjetivamente pueda considerarse "muy por encima de ellas", en verdad no hace más que expresar esas relaciones en su propia persona. La sociedad es, en efecto, el conjunto de interacciones que los individuos realizan entre sí, y estas relaciones no dependen de cada voluntad particular, muy por el contrario, son estas voluntades las que están en una situación de dependencia respecto de la estructura que modela el conjunto de esas relaciones, pues cada uno debe alcanzar su propio fin privado "en el ámbito de las condiciones que fija la sociedad y con los medios que ella ofrece" (Marx, 2007, p. 84).

Así pues, la perspectiva teórica que parte del análisis de los individuos para comprender sus motivaciones, comportamientos y actividades a partir de una racionalidad, que se supone posee cada persona, para poner en práctica la 
búsqueda de sus fines, se torna inadecuado e insuficiente ${ }^{8}$, pues no solo omite la existencia y el funcionamiento de estructuras sociales, políticas y económicas reales, sino que vela su configuración injusta y desigual. Y si bien es cierto que el estudio del comportamiento de los hombres puede arrojar resultados que expliquen de algún modo ciertas estructuras sociales en las cuales ellos están inmersos, lo cierto es que este por sí no permite entender el conjunto de ordenamientos conforme a los cuales estos individuos forman sus aspiraciones y ordenan sus prácticas y acciones en un marco social establecido.

\section{Referencias}

Berardi, F. (2003). La fábrica de la infelicidad. Nuevas formas de trabajo y movimiento global. Madrid: Edición Traficantes de Sueños.

Bedoya, M. (2018). La gestión de sí mismo. Medellín: Universidad de Antioquia.

Castro-Gómez, S. (2010). Historia de la gubernamentalidad. Razón de Estado, liberalismo y neoliberlismo en Michel Foucault. Bogotá: Siglo del Hombre.

Confecámaras (2018). Informe de dinámica empresarial en Colombia. 2017. Recuperado de http://confecamaras.org.co/phocadownload/2017/ Informe_din\%C3\%A1mica_empresarial/Informe_de_Din\%C3\%A1 mica Empresarial_2017.pdf

Coronel, J. (2018). Plataformas digitales: relación laboral disfraza. Agencia de información laboral. Recuperado de http://ail.ens.org.co/opinion/plataformasdigitales-relacion-laboral-disfrazada/

Foucault, M. (2007). Nacimiento de la biopolítica (curso en el Collège de France, 1978-1979). Buenos Aires: Fondo de Cultura Económica.

Godelier, M. (1975). Racionalidad e irracionalidad en economía. Ciudad de México: Siglo XXI Editores.

Gómez, A. (2017). El Empresario de sí mismo. El olvido de Antonio Negri. Daimon, Revista Internacional de Filosofía, (71), 63-79.

\footnotetext{
${ }^{8}$ En su libro La teoría política del individualismo posesivo, C. B. Macpherson hace una lectura contextual de las obras de Hobbes y Locke para mostrar que estas teorías, más que representar meras ideas filosóficas, expresaban realmente relaciones muy concretas propias de la época en la que ellas surgieron. En este sentido podemos decir con M. Godelier que estos autores "parten de hecho del sistema para analizar el comportamiento de los individuos, aunque pretenden deducir el sistema de los individuos" (Godelier, 1975, p. 73).
} 
Heinrich, M. (2018). Crítica de la economía política. Una introducción a El capital de Marx. Madrid: Escolar y Mayo Editores.

Hope, K. (2018). El 1\% de los ricos del mundo acumula el $82 \%$ de la riqueza global (y las críticas a estas cifras de Oxfam). BBC News. Recuperado de https:// www.bbc.com/mundo/noticias-42776299

Laval, C. y Dardot, P. (2013). La nueva razón del mundo. Ensayo sobre la sociedad neoliberal. Barcelona: Gedisa.

Macpherson, C. (2005). La teoría política del individualismo posesivo. De Hobbes a Locke. Madrid: Trotta.

Martínez, J. (2013). El dispositivo, una grilla de análisis en la visibilización de las subjetividades. Tabula Rasa, (19), 79-99.

Marx, K. (1970). Manuscritos economía y filosofía. Madrid: Alianza Editorial.

Marx, K. (2000). El capital. Libro I. Capítulo VI (inédito). Ciudad de México: Siglo XXI Editores.

Marx, K. (2007) Elementos fundamentales para la crítica de la economía política (Grundrisse) 1857-1858. Ciudad de México: Siglo XXI Editores.

Marx, K. (2014a). El capital. Ciudad de México: Fondo de Cultura Económica.

Marx, K. (2014b). La ideología alemana. Madrid: Akal.

Postone, M. (2006). Tiempo, trabajo y dominación social. Madrid: Editorial Marcial Pons.

Romo, N. (5 de septiembre de 2016). 70\% de empresas creadas fracasan antes de sus primeros cinco años. El Heraldo. Recuperado de https://www.elheraldo. co/economia/comfecamaras-70-de-empresas-creadas-fracasan-antes-de-susprimeros-5-anos-283021

Schmidt, A. (2011). El concepto de naturaleza en Marx. Madrid: Siglo XXI Editores.

Vega, C. (1 de septiembre de 2016). Solo el 29\% de las nuevas empresas sobreviven en Colombia. El Espectador. Recuperado de https://www.elespectador. com/noticias/economia/solo-el-29-de-nuevas-empresas-sobreviven-colombiaarticulo-652414 